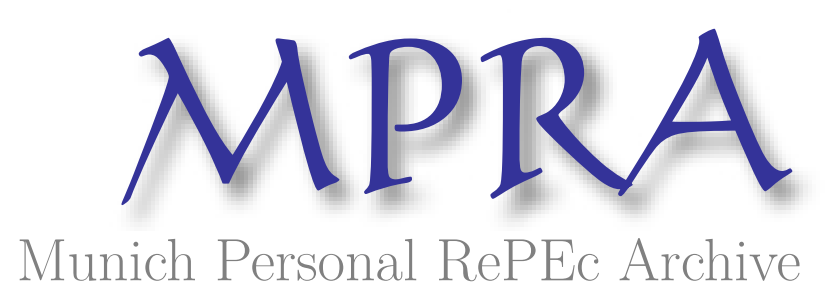

\title{
Household expenditure components and the poverty and inequality relationship in Malawi
}

Mussa, Richard

Chancellor College, University of Malawi

1 June 2011

Online at https://mpra.ub.uni-muenchen.de/31225/

MPRA Paper No. 31225, posted 01 Jun 2011 13:39 UTC 


\title{
Household Expenditure Components and the Poverty and Inequality Relationship in Malawi
}

\author{
Richard Mussa*
}

\begin{abstract}
The paper looks at how inequality in household expenditure components affects total inequality and poverty in Malawi. Total household expenditure is disaggregated into four mutually exclusive and exhaustive expenditure items namely; expenditure on food, expenditure on health, expenditure on education, and expenditure on non food and non human capital items. Using data from the second integrated household survey (IHS2), we find that the elasticities of poverty with respect to within-component and between-component inequality are positive, suggesting that an increase within-component and between-component inequality increases overall poverty in Malawi. The results also show that the elasticities of poverty, as measured by the poverty gap and poverty indices, with respect to inequalities in expenditure on food and health are positive and are about the same in magnitude. The results vindicate the exemptions and zero rating of some food, health, and education related goods and services under the Value Added Tax (VAT) system. More importantly, they also suggest that expanding the coverage of zero rating and exemption would have a poverty reducing effect. These findings hold at the national level, as well as when rural and urban areas are treated separately. Additionally, the results are insensitive to choice of poverty line.
\end{abstract}

Key words: Inequality; poverty; Malawi.

\section{Introduction}

The reduction of poverty in Malawi, similar to many developing countries is a primary goal of development strategy. As part of the global fight against poverty, Malawi is committed to the Millennium Development Goals (MDGs) which seek to among other things eradicate extreme poverty and hunger. Over the years, the Malawian government has pursued poverty reduction efforts through various strategies emphasizing economic growth, infrastructure development, and

\footnotetext{
*Department of Economics, Chancellor College, University of Malawi, Box 280, Zomba, Malawi, rimussa@yahoo.co.uk.
} 
the provision of basic social services. These strategies include; the Poverty Alleviation Programme in 1994 (GOM, 1994), the Malawi Poverty Reduction Strategy (GOM, 2002) for the period 2002-2005, and recently, the first Malawi Growth and Development Strategy (MGDS) for the period 2006-2011 (GOM, 2006). A follow up MGDS will cover the period 2011-2016 . Despite these policies, poverty and inequality remain high. For instance, the percentage of the poor in 1998 was 54 per cent but declined slightly to 52 per cent in 2005. This decline was found to be statistically insignificant. Additionally, the Gini coefficient for 1998 and 2005 was 0.39, suggesting that inequality remained high and unchanged (World Bank, 2006). The aforementioned poverty reduction strategies emphasise sustainable economic growth as a mechanism for reducing poverty.

There is consensus in the development economics literature that economic growth is necessary but not sufficient for reducing poverty. The impact of economic growth on poverty depends on how the benefits of growth are distributed across the population. Ravallion (2001) finds that of those countries which registered improvements in living standards in a sample of 50 developing countries, the reduction in poverty is larger for those countries where inequality is falling. Similarly, Fosu (2009) finds that the impact of income growth on poverty reduction in a number of sub-Saharan African and non- sub-Saharan African countries is a decreasing function of initial inequality. Inequality directly and indirectly - through its relationship with economic growth - affects the level of poverty. Poverty, growth, and inequality are inextricably linked. A development strategy must therefore take into account this poverty-growth-inequality nexus. Bourguignon (2004) argues that to reduce poverty, a development strategy must reduce inequality, on the one hand, and increase both income levels and economic growth on the other hand.

Using Malawian micro data, this paper focuses on the direct link which runs from inequality to poverty. Two issues are addressed. First, we examine the impact of inequality within household expenditure components on both total inequality and poverty. Second, the paper explores the effect of inequality between household expenditure components on overall inequality and poverty. Araar and Duclos (2010) look at the impact of within-income component and between-income component inequality on poverty in Nigeria. To the best of our knowledge, no study has looked at the impact of within-expenditure component and between-expenditure

\footnotetext{
${ }^{1}$ At the time of writing this paper, a draft MGDS for 2011-2016 was under review.
} 
component inequality on poverty. Focusing on household consumption expenditure other than income in a developing country context has some advantages. Household consumption expenditure is a more reliable indicator of welfare for two reasons. First, particularly in an agricultural economy such as Malawi, income is often very lumpy. Farming households receive a large amount of cash income in May and June after the harvest, and receive very little the rest of the year. Consumption expenditure is a smoother measure of welfare through time than is income. In other words, consumption can be viewed as realized welfare, whereas income is more a measure of potential welfare (Murkhejee and Benson, 2003). Second, in Malawi much of household income is derived from self-employed business or subsistence-oriented agricultural production. Assigning income values to the proceeds of these enterprises is often problematic (Hentschel and Lanjouw, 1996). In addition to the fact that household consumption expenditure is a better welfare indicator, focusing on expenditure enables the examination of the role of fiscal policy in poverty reduction. For example, a finding that the marginal impact of withincomponent inequality for a component is positive, may imply that a tax increase or a lifting of a tax exemption on the commodity would increase within-component inequality which in turn would increase overall poverty. An appropriate poverty-reducing fiscal policy in this case would be to reduce tax or exempt the commodity from tax.

The rest of the paper is structured as follows. Section 2 presents the methodology as well as a description of the data used in this paper. Empirical results are the focus of Section 3. Finally, Section 4 concludes.

\section{Methodology}

In order to examine the impact on overall inequality and poverty of changes in household expenditure components we adopt a methodology developed by Araar and Duclos (2010). It provides a micro framework which allows the examination of three things namely; the individual impact of inequality within each expenditure component on overall poverty and inequality, the joint impact of inequality within all expenditure components on overall poverty and inequality, and finally, the impact of inequality between expenditure components on overall poverty and inequality.

\subsection{Within-Component Inequality}

Assume that each household has a total of $K$ mutually exclusive and exhaustive expenditure components, $k=1 \ldots K$, and also denote the expected amount of expenditure component $k$ found 
at percentile $p$ by $s(p ; k)$. $s(p ; k)$ can be increasing or decreasing with $p$, it can also be negative. The amount of expenditure found at percentile $p$ is then given as

$$
Q(p)=\sum_{k=1}^{K} s(p ; k)
$$

An increase in the bipolarisation of expenditure component $k$ (within component $k$ inequality) can be modeled as an increase the distance between the overall mean of each expenditure component, $\mu(k)$ and the individual value of all expenditure components. If we let $\eta(k)$ be a component- $k$ - specific factor of bipolarization, it can alternatively be derived by adding $(\eta(k)-1)((\mu k)-s(p ; k))$ to $s(p ; k)$ in such a way that expected post-bipolarisation expenditure at percentile $p$ becomes

$$
Q(p ; \eta(k))=Q(p)+(\eta(k)-1)(s(p ; k)-\mu(k))
$$

An increase in bipolarisation of an expenditure component would occur with policies which end up creating a two tier system in terms of quality of say health and education. For instance, the introduction of free primary education in Malawi in 1994 led to a reduction in quality of public schools (which are not expensive) this in turn led to a mushrooming of expensive private schools. Thus, while the variation in spending on education was low prior to 1994, it has increased after.

Let the overall single-parameter Gini (S-Gini) coefficient ${ }^{2}$ after the bipolarisation factor $\eta(k)$ has been applied to component $k$ be given as

$$
\left.I(\rho ; \eta(k))=\mu^{-1} \int[\mu-Q(p)+(\eta(k)-1)(s(p ; k)-\mu(k)))\right] \omega(p ; \rho) d p
$$

The marginal impact on inequality as measured by the S-Gini coefficient (equation 3) of a change in within-component inequality, $\eta(k)$ is then expressed as

\footnotetext{
${ }^{2}$ The single-parameter Gini (S-Gini) coefficient introduced by Donaldson and Weymark (1980, 1983), and Yitxhaki (1983) is given as $I(p ;)=\mu^{-1} \int_{0}^{1}[\mu-(Q(p)] \omega(p ; \rho) d p$, where $\omega(p ; \rho)$ is an ethical weight. $\rho$ is a parameter of inequality aversion that determines our ethical concern for the deviation of quantiles from the mean at various ranks in the population. The higher is $\rho$, the higher is aversion to inequality. When $\rho=2$, the S-Gini coefficient reduces to the ordinary Gini coefficient.
} 


$$
\left.\frac{\partial I(\rho ; \eta(k))}{\partial \eta(k)}\right|_{\eta(k=1)}=\frac{\mu(k)}{\mu} \operatorname{IC}(\rho ; k),
$$

where $\mu(k) / \mu$ is the share of expenditure component $k$ in total expenditure, and $I C(\rho ; k)$ is a coefficient of concentration of component $k$ given as

$$
I C(\rho ; k)=\mu^{-1} \int(s(p ; k)-\mu(k)) \omega(p ; \rho) d p .
$$

It is a measure of within-component inequality since it depends only on the distances between $\mu(k)$ and expected amount of expenditure component $k$ found at percentile $p$. Thus, the impact on total inequality of an increase in inequality within a given component depends both on the expenditure share and on the concentration index of that component. Equation 4 gives the individual impact of inequality in each component on overall inequality. To capture the joint impact of inequality in all the components on total inequality, the same $\eta(k)$ is applied to all components.

Letting $z$ be a poverty line, and $\alpha$ a poverty aversion parameter, the Foster et al. (1984) (FGT) class of poverty indices after the bipolarisation factor $\eta(k)$ has been applied denoted by $P(z ; \alpha ; \eta(k))$ is expressed as

$$
P(z ; \alpha ; \eta(k))=\int_{0}^{1}\left(\frac{z-Q(p ; \eta(k))}{z}\right)_{+}^{\alpha} d p
$$

The marginal impact on total poverty of within-component inequality is then derived as

$$
\frac{\partial P(z ; \alpha ; \eta(k))}{\partial \eta(k)}=\left\{\begin{array}{l}
\alpha z^{-1} \mu(k)[P(z ; \alpha-1)-\overline{C D}(z ; \alpha ; k)] \text { if } \alpha>0 \\
-f(z)(s(F(z) ; k)-\mu(k)) \text { if } \alpha=0
\end{array}\right.
$$

$f(z)$ and $F(z)$ are respectively the probability and cumulative density functions at $z$. $\overline{C D}(z ; \alpha ; k)$ is a normalised consumption dominance curve for component $k$ as developed by Makdissi and Wodon (2002). It is given as 


$$
\overline{C D}(z ; \alpha ; k)=\int_{0}^{1}\left(\frac{z-Q(p)}{z}\right)_{+}^{\alpha-1} \frac{s(p ; k)}{\mu(k)} d p
$$

The sign of the marginal impact of within-component inequality on poverty (equation 7) depends on $z, \alpha, \mu(k)$ and the distribution of $s(p ; k)$. If we look at the poverty headcount $(\alpha=0)$ for instance, the sign depends on the difference between the expected level of expenditure component $k$ at the poverty line and the overall mean value of that component. If $s(F(z) ; k)$ exceeds $\mu(k)$, the headcount will fall following an increase in the inequality of component $k$. Equation 7 measures the individual impact of inequality in each component on overall poverty. The joint impact of inequality in all the components on total poverty is measured by applying the same $\eta(k)$ to all components.

Bringing together the impact of within-component inequality on total inequality (equation 4) and on total poverty (equation 7), the elasticity of total poverty with respect to withincomponent inequality denoted as $\varepsilon_{\eta(k)}(z ; \alpha ; \rho)$ is then given by

$$
\varepsilon_{\eta(k)}(z ; \alpha ; \rho)=\left.\frac{\partial P(z ; \alpha ; \eta(k)) / \partial \eta(k)}{\partial I(\rho ; \eta(k)) / \partial \eta(k)} \frac{I(\rho ; \eta(k))}{\partial P(z ; \alpha ; \eta(k))}\right|_{\eta(k)=1}
$$

Equation 9 essentially captures individual elasticities, and to get joint elasticities where the components are looked at together we let $\eta$ be the case in which the same $\eta(k)$ is concurrently applied to all components. The elasticity of total poverty with respect to the joint withincomponent inequality is then given as

$$
\varepsilon_{\eta}(z ; \alpha ; \rho)=\left.\frac{\partial P(z ; \alpha ; \eta / \partial \eta}{\partial I(\rho ; \eta) / \partial \eta} \frac{I(\rho ; \eta)}{\partial P(z ; \alpha ; \eta)}\right|_{\eta=1}
$$

\subsection{Between-Component Inequality}

We now look at how to measure the impact of a bipolarisation process on overall poverty and inequality that spreads components apart from each other without affecting within-component inequality. The disparity in spending components may arise for example from changes in relative prices of commodities. For instance, an increase in the cost of food, a necessity, may lead to a situation where food sellers benefit through an increase in income such that they start spending more on luxuries, at the same time food buyers would reduce spending on luxury items and redirect their income to food. To measure the impact of between-component inequality on 
inequality and poverty both within-component inequality and the overall mean expenditure are held constant, and this is done by defining a component-specific factor of change $\tau(k)$ in the average of component $k$,

$$
\tau(k)-1=1+(\tau-1)\left(1-\frac{\mu / K}{\mu(k)}\right)
$$

The expected post-bipolarisation of component $k$ at percentile $p$ is then given by

$$
s(p ; k)\left(1+(\tau-1)\left(\sum_{k=1}^{K}\right)\right)
$$

By multiplying $s(p ; k)$ by a factor that is independent of $p$ ensures that within component $k$ inequality is held constant. Besides, the common factor $\tau$ also ensures that the overall mean of expenditure is constant.

After the between-component bipolarisation factor, $\tau$ has been applied to the S-Gini coefficient, the marginal impact of between-component inequality on overall inequality equals

$$
\left.\frac{\partial I(\rho ; \tau)}{\partial \tau}\right|_{\tau=1}=\left[I-\sum_{k=1}^{K} \frac{I C(\rho ; k)}{K}\right]
$$

The marginal impact of between-component inequality on overall poverty as measured by a postbipolarisation FGT is expressed as

$$
\left.\frac{\partial P(z ; \alpha ; \tau)}{\partial \tau}\right|_{\tau=1}=\left\{\begin{array}{l}
\alpha\left[p(z ; \alpha)-P(z ; \alpha-1)+\frac{\mu}{z} \sum_{k=1}^{K} \frac{C D(z ; \alpha ; k)}{K} \text { if } \alpha>0\right. \\
-f(z) \sum_{k=1}^{K} s(F(z) ; k)\left(1-\frac{\mu / K}{\mu(k)}\right) \text { if } \alpha=0
\end{array}\right.
$$

Putting everything together, the elasticity of total poverty with respect to between-component inequality is then is expressed as

$$
\varepsilon_{\tau}(z ; \alpha ; \rho)=\left.\frac{\partial P(z ; \alpha ; \tau) / \partial \tau}{\partial I(\rho ; \tau) / \partial \tau} \frac{I(\rho ; \tau)}{P(z ; \alpha ; \tau)}\right|_{\tau=1}
$$


The poverty impact of between-component inequality is qualitatively ambiguous as the sign depends on $\frac{\mu / K}{\mu(k)}$, and on $P(z ; \alpha-1)$.

\subsection{Data}

The paper uses cross sectional data taken from the second Malawi integrated household survey (IHS2). This is a nationally representative sample survey designed to provide information on the various aspects of household welfare in Malawi. It was conducted by the National Statistical Office from March 2004-April 2005. Information, which included household expenditure on different items, was collected from a nationally representative sample of 11,280 households. The household expenditures also include excise and sales taxes, of goods and services purchased.

We disaggregate total household expenditure measured in Malawi Kwacha (MK) into four mutually exclusive and exhaustive expenditure components as follows:

- Food: expenditure on food, and beverages including food and beverages consumed from vendors and cafes;

- Non-food and non-human capital: expenditure on non-food and non-human capital items. This consists of alcohol and tobacco, clothing and footwear, imputed housing rent, household utilities and regular maintenance of housing, entertainment, personal care and use value of durable goods;

- Education: expenditure on the following education items; school fees (tuition and boarding), books and other materials, school uniform, contributions to school building and maintenance, parental association fees, and other school related expenses;

- Health: health expenditure covering hospitalization (including traditional healer), drugs, and out-patient expenses.

\section{Estimation Results}

The empirical analysis is done at both the national level as well as the rural and urban level. All the household expenditure components and the total household expenditure are annualized and expressed in per capita terms. As indicated in the methodology section, the analysis is predicated on a poverty line, we therefore use $z=M K 16165$ (approximately US\$145.50) per year as our poverty line. This poverty line called the 'poor poverty line' was defined by the National Statistical Office of Malawi (NSO) for 2004/2005. As a sensitivity check we also use $z=M K 10029$, which is another NSO-defined poverty line. This is called the 'ultra poor poverty 
line'. To measure poverty, the paper uses three FGT indices namely; the poverty headcount, $\alpha=0$, the poverty gap index, $\alpha=1$, and the poverty severity index, $\alpha=2$. In terms of inequality measurement, the paper uses the S-Gini coefficient where $\rho=2$ (the ordinary Gini coefficient).

Table 1 reports poverty indices and Gini coefficients for Malawi. The poverty headcount for rural areas is about 56 per cent while that for urban areas is 25 per cent, suggesting that there are more poor people in rural areas than in urban areas. In contrast, the Gini coefficient for rural areas is lower than that for urban areas, implying that rural areas in Malawi are more equal than urban areas. Table 2 presents shares of the four expenditure components in total household expenditure and the means of the components. At the national level, the results show that at about 57 per cent, the share of household spending on food out of total household spending is the largest, while household spending on health has the lowest share. The results also show that about 60 per cent of household spending in rural areas goes to food as compared to 45 per cent in urban areas. This difference is largely a reflection of the higher poverty in rural areas. Interestingly, the proportion of household spending going to health is slightly larger in rural areas than in urban areas, at the same time the share of spending dedicated to education by urban households is almost twice that by rural households. Looking at the average spending on education in the two areas, the difference is more pronounced, with an average of MK165 in rural areas compared to MK1118 in urban areas.

We now look at the estimation results of the relationship between poverty and inequality in Malawi. Table 3 presents national level marginal impacts of within-component and betweencomponent inequality on poverty and inequality. Elasticities of poverty with respect to withincomponent and between-component inequality are also reported. The magnitudes of the elasticities for within-component and between-component inequalities vary noticeably across the poverty indices. For the poverty headcount, the elasticity of poverty with respect to withincomponent is smaller than that for between-component inequality while the reverse holds for the poverty gap and poverty severity indices. Regardless of poverty index used, the signs of the marginal impacts of within-component inequality on overall inequality and poverty are all positive. Consequently, the corresponding elasticities are positive. In contrast, the signs of the marginal impacts of between-component inequality on inequality and poverty are all negative, and as a result, the elasticities are all positive. These findings suggest that an increase within- 
component and between-component inequality increases overall poverty in Malawi. The results also suggest that the effects of within-component and between-component inequalities on overall poverty and inequality work in opposite directions. Specifically, an increase in withincomponent inequality increases total poverty and inequality, while an increase in betweencomponent inequality decreases total poverty and inequality.

The results have useful and insightful policy relevance. With respect to marginal impacts of within-component inequality on inequality, the results can be used to examine the distributional effect of imposing a commodity percentage tax or a tax exemption. When the marginal impact of within-component inequality for a component is positive, a tax increase or a lifting of a tax exemption on the commodity would increase within-component inequality which in turn would increase overall inequality. In the case of a tax, such an increase would be regressive since it affects the poor more than it affects the rich at the margin. In this case an appropriate policy aimed at reducing overall inequality would be to reduce tax or exempt the commodity from tax. When the marginal impact of within-component inequality is negative, a tax increase or a lifting of tax exemption on the commodity would increase within-component inequality which in turn would reduce overall inequality, as would be expected from a tax which is progressive. As shown already, the signs of the marginal impacts of inequality in the four components on overall inequality are all positive suggesting a tax reduction or a tax exemption would have an equalizing effect.

Similar to the case of inequality in the foregoing, the results for the marginal impacts of within-component inequality on poverty together with their corresponding elasticities can be used to examine the poverty effect of imposing a commodity percentage tax or a tax exemption. When the marginal impact of within-component inequality for a component is positive, a tax increase or a lifting of a tax exemption on the commodity would increase within-component inequality which in turn would increase overall poverty. A poverty alleviation policy in this situation would be to reduce tax or exempt the commodity from tax. Conversely, when the marginal impact of within-component inequality on poverty is negative, a tax increase or a lifting of a tax exemption would increase within-component inequality which in turn would reduce overall poverty. The signs of the marginal impacts of within-group inequality in Table 3 are all positive, suggesting that a tax reduction or an exemption on the four items would go a long way in reducing poverty. The differences in the magnitude of the elasticities indicate that the 
responsiveness of poverty to within-component inequality is also different. Reducing inequality in spending on food and health has the largest poverty reducing effect. More specifically, and looking at the poverty gap and poverty severity indices respectively, reducing inequality in food and health by 1 per cent would reduce overall poverty in Malawi by about 2 per cent. This is an economically substantial effect. Inequality in non-food and non-human capital spending has the smallest effect on poverty. This means that a poverty reduction strategy which focuses more on reducing inequality in spending on food, health, and education would be more effective in reducing poverty.

The national results just discussed might mask possible differences in the relationship between poverty and inequality which may exist between rural and urban areas. Tables 4 and 5 contain marginal impacts of within-component and between-component inequality on poverty and inequality in rural and urban areas respectively. Elasticities of poverty with respect to within-component and between-component inequality are also presented. In both areas, the signs of the marginal impacts of within-component inequality are all positive while they are negative for the between-component inequality. Besides, in the two areas, the signs of elasticities of poverty with respect to within-component and between-component inequality are positive. Furthermore, inequalities in health have the largest effect on poverty and inequality in the two areas. Interestingly, the results reveal that elasticities for urban areas are larger than those for rural areas. This implies that overall poverty and inequality in urban areas is more responsive to changes in within-component and between-component inequalities. Using the poverty gap for instance, the results show that a 1 per cent reduction in inequality in health reduces poverty by 1.4 per cent in rural areas and by 8 per cent in urban areas.

The above discussion is based on the 'poor poverty line', which is higher than the 'ultra poor poverty line'. In order to assess the sensitivity of the results to choice of poverty line, the above analysis was repeated using the 'ultra poor poverty line'. Appendix Table A1 reports national level results, while rural and urban results are contained in Tables A2 and A3 respectively. Three findings emerge from the results. First, compared to the previous results, all the elasticities for this lower poverty line are larger. Second, the signs of the marginal impacts and elasticities are the same as those found earlier. Third, the ranking of the inequality within the expenditure components is not reversed; inequality in health spending has the largest impact on both overall poverty and inequality. These findings give us confidence that the conclusions and 
implications derived are valid regardless of which official poverty line is used. It should be noted that for the 'poor poverty line', the orderings of within-component and between-component inequalities in terms of the magnitudes of the elasticities when the poverty headcount is used are largely inconsistent. It is however clear and unambiguous for the poverty gap and poverty severity indices. Significantly, for the 'ultra poor poverty line' all the three poverty indices convey the same picture.

The results in the paper point to an important role tax policy can play in the fight against poverty and inequality in Malawi. Of special interest is the sales tax, which represents an increase in the price of goods and services acquired by households. The sales tax in Malawi also known as the Value Added Tax (VAT) categorizes goods and services as follows; standard rated goods and services which attract a standard VAT rate ${ }^{3}$, zero rated goods and services with a 0 per cent tax rate, and exempt goods and services. The difference between zero rated and exempt goods and services is that for zero rated goods and services tax payers may claim VAT on purchases while they don't for exempt goods and services. Basically, both do not collect any VAT on sales. Most, not all, food, health, and education items are either exempted or zero rated ${ }^{4}$. While the results here vindicate the exemptions and zero rating of food, health, and education related goods and services, they also suggest that expanding the coverage of zero rating and exemption would have an equalizing and a poverty reducing effect. The spending inequalities especially for health and education may stem from a much deeper structural problem which tax policy working through the price mechanism cannot address. Spending inequalities in health and education may just be a reflection of inequality in quality of health and education services which emanate from a two-tier service system. Thus, to fight health and education spending inequality entails reducing the variation in quality of health and education services through ensuring the delivery of good quality health and education services by government.

\section{Concluding Remarks}

The paper has explored how inequality in household expenditure components impacts on total inequality and poverty in Malawi. Using data from the second integrated household survey (IHS2), we have disaggregated total household expenditure into four mutually exclusive and

\footnotetext{
${ }^{3}$ At the time of writing this paper, it was pegged 16.5 per cent.

4 The Value Added Tax (VAT) Act of 2006 provides the legal framework for the administration and collection of VAT. The First Schedule of the Act provides exempted goods and services, while zero rated goods and services are contained in the Second Schedule. The VAT Act is available on this link: http://www.mra.mw.
} 
exhaustive expenditure items namely; expenditure on food, expenditure on health, expenditure on education, and expenditure on non food and non human capital items. The results indicate that an increase in within-component inequality increases total poverty and inequality, while an increase in between-component inequality decreases total poverty and inequality. We find that the elasticities of poverty with respect to within-component and between-component inequality are positive, suggesting that an increase within-component and between-component inequality increases overall poverty in Malawi. The results also show that the elasticities of poverty, as measured by the poverty gap and poverty indices, with respect to inequalities in expenditure on food and health are positive and are about the same in magnitude. The results vindicate the exemptions and zero rating of some food, health, and education related goods and services under the VAT system. More importantly, they also suggest that expanding the coverage of zero rating and exemption would have a poverty reducing effect. These findings hold at the national level, as well as when rural and urban areas are treated separately. Additionally, the results are insensitive to choice of poverty line.

\section{References}

ARAAR, A. and J.-Y. DUCLOS (2010). Poverty and Inequality: A Micro Framework. Journal of African Economies, 19: 357-398.

BOURGUIGNON, F. (2004). The Poverty-Growth-Inequality Triangle. Paper Presented at the Indian Council for Research on International Economic Relations.

DONALDSON, D. and J. WEYMARK (1980). A Single Parameter Generalisation of the Gini Indices of Inequality. Journal of Economic Theory, 22: 67-86.

DONALDSON, D. and J. WEYMARK (1983). Ethically Flexible Gini Indices for Income Distributions in the Continuum. Journal of Economic Theory, 29: 353-358.

FOSTER, J., J. GREER and E. THORBECKE (1984). A Class of Decomposable Poverty Measure. Econometrica, 52: 761-776.

FOSU, A. K. (2009). Inequality and the Impact of Growth on Poverty; Comparative Evidence for Sub-Saharan Africa. Journal of Development Studies, Vol. 45: 726-745.

GOM (Government of Malawi) (1994). Poverty Alleviation Programme. Lilongwe: Ministry of Economic Planning and Development.

GOM (Government of Malawi) (2002). Malawi Poverty Reduction Strategy Paper. Lilongwe: Ministry of Economic Planning and Development. 
GOM (Government of Malawi) (2006). Malawi Growth and Development Strategy. Lilongwe: Ministry of Economic Planning and Development.

HENTSCHEL, J., and P. LANJOUW (1996). Constructing an indicator of consumption for the analysis of poverty: Principles and illustrations with reference to Ecuador. Living standards measurement study working paper no. 124. The World Bank, Washington, DC.

MUKHERJEE, S and T. BENSON (2003). The Determinants of Poverty in Malawi. World Development, 31: 339-358.

RAVALLION, M. (2001). Growth, inequality, and poverty: Looking beyond averages. World Development, 29:1803-1815.

WORLD BANK (2006). Malawi Poverty and Vulnerability Assessment: Investing in Our Future. Washington, D.C: World Bank.

YITZHAKI, S. (1983). On an Extension of the Gini Index. International Economic Review, 24: 617-628. 
Table 1: Poverty and Inequality in Malawi

\begin{tabular}{lccc}
\hline \hline FGT Index/Gini Coefficient & National & Rural & Urban \\
\hline Poverty Headcount Index $(\alpha=0)$ & 52.4 & 55.9 & 25.4 \\
Poverty Gap Index $(\alpha=1)$ & 0.178 & 0.192 & 0.071 \\
Poverty Severity Index $(\alpha=2)$ & 0.080 & 0.086 & 0.028 \\
& & & \\
\hline Gini Coefficient $(\rho=2)$ & 0.390 & 0.339 & 0.484 \\
\hline \hline
\end{tabular}

Notes: The poverty line is MK16165. The poverty headcount index has been multiplied by 100 .

Table 2: Share and mean of expenditure component

\begin{tabular}{lccccccc}
\hline \hline Expenditure Component & \multicolumn{2}{c|}{ National } & \multicolumn{2}{c|}{ Rural } & \multicolumn{2}{c}{ Urban } \\
\hline & Share (\%) & Mean & Share (\%) & Mean & Share (\%) & Mean \\
\hline Food & 56.53 & 14172.63 & 59.76 & 13002.77 & 45.31 & 22166.67 \\
Non human & 40.47 & 9955.13 & 37.73 & 8159.50 & 49.96 & 22225.24 \\
Education & 1.69 & 286.41 & 1.13 & 164.77 & 3.63 & 1117.60 \\
Health & 1.32 & 294.46 & 1.39 & 267.52 & 1.10 & 478.55 \\
\hline \hline
\end{tabular}

Notes: All components and total household expenditure are in per capita terms and they are annualized.

Expenditure share is the component mean divided by the mean of total expenditure, $\frac{\mu(k)}{\mu}$. 
Table 3: Elasticity of Poverty with Respect to Within- and Between-Component Inequality $(\rho=2)$ at the National Level

\begin{tabular}{lccccccccc}
\hline & \multicolumn{3}{c}{$\underline{\alpha=0}$} & & \multicolumn{3}{c}{$\underline{\alpha=1}$} & & \multicolumn{2}{c}{$\alpha=2$} \\
Source & MII & MIP & ELS & MII & MIP & ELS & MII & MIP & ELS \\
\hline Food & 0.001923 & 0.000817 & 0.316096 & 0.001923 & 0.001728 & 1.971192 & 0.001923 & 0.000707 & 1.796458 \\
Non human & 0.001830 & 0.001134 & 0.461161 & 0.001830 & 0.001538 & 1.842335 & 0.001830 & 0.000592 & 1.580026 \\
Education & 0.000104 & 0.000087 & 0.624177 & 0.000104 & 0.000083 & 1.737043 & 0.000104 & 0.000030 & 1.387215 \\
Health & 0.000043 & 0.000018 & 0.304009 & 0.000043 & 0.000039 & 1.988076 & 0.000043 & 0.000016 & 1.806613 \\
Within & 0.003900 & 0.001993 & 0.380353 & 0.003900 & 0.003387 & 1.904650 & 0.003900 & 0.002688 & 3.368126 \\
Between & -0.000446 & -0.000637 & 1.062737 & -0.000446 & -0.000294 & 1.446337 & -0.000446 & -0.000152 & 1.663215 \\
\hline \hline
\end{tabular}

Notes: MII is the marginal impact on inequality, $\frac{\partial I(\rho)}{\partial(.)} ;$ MIP, is the marginal impact on poverty, $\frac{\partial P(z ; \alpha)}{\partial(.)}$; and ELS is the elasticity of poverty with respect to inequality, $\varepsilon_{(.)}(z ; \alpha ; \rho)$. The poverty line is MK16165. 
Table 4: Elasticity of Poverty with Respect to Within- and Between-Component Inequality $(\rho=2)$ for Rural Areas

\begin{tabular}{|c|c|c|c|c|c|c|c|c|c|}
\hline & & $\underline{\alpha=0}$ & & & $\underline{\alpha=1}$ & & & $\underline{\alpha=2}$ & \\
\hline Source & MII & MIP & ELS & MII & MIP & ELS & MII & MIP & ELS \\
\hline Food & 0.001905 & 0.000452 & 0.144104 & 0.001905 & 0.001544 & 1.435422 & 0.001905 & 0.000658 & 1.355163 \\
\hline Non human & 0.001398 & 0.000529 & 0.229614 & 0.001398 & 0.001104 & 1.398622 & 0.001398 & 0.000453 & 1.272403 \\
\hline Education & 0.000048 & 0.000031 & 0.392567 & 0.000048 & 0.000038 & 1.407306 & 0.000048 & 0.000015 & 1.203537 \\
\hline Health & 0.000041 & 0.000007 & 0.098724 & 0.000041 & 0.000033 & 1.447288 & 0.000041 & 0.000014 & 1.389722 \\
\hline Within & 0.003392 & 0.000957 & 0.171377 & 0.003392 & 0.002720 & 1.419999 & 0.003392 & 0.002280 & 2.638649 \\
\hline Between & -0.000136 & -0.000328 & 1.464501 & -0.000136 & -0.000109 & 1.414648 & -0.000136 & -0.000048 & 1.381366 \\
\hline
\end{tabular}

Notes: MII is the marginal impact on inequality, $\frac{\partial I(\rho)}{\partial(.)}$; MIP, is the marginal impact on poverty, $\frac{\partial P(z ; \alpha)}{\partial(.)}$; and ELS is the elasticity of poverty with respect to inequality, $\mathcal{E}_{(.)}(z ; \alpha ; \rho)$. The poverty line is MK16165. 
Table 5: Elasticity of Poverty with Respect to Within- and Between-Component Inequality ( $\rho=2$ ) for Urban Areas

\begin{tabular}{lccccccccc}
\hline & & $\underline{\alpha}=0$ & & & $\underline{\alpha=1}$ & & & $\underline{\alpha=2}$ \\
Source & MII & MIP & ELS & MII & MIP & ELS & MII & MIP & ELS \\
\hline Food & 0.001694 & 0.002548 & 2.866243 & 0.001694 & 0.001852 & 7.493838 & 0.001694 & 0.000570 & 5.753453 \\
Non human & 0.002852 & 0.004071 & 2.719973 & 0.002852 & 0.002607 & 6.264321 & 0.002852 & 0.000756 & 4.527250 \\
Education & 0.000250 & 0.000363 & 2.761597 & 0.000250 & 0.000213 & 5.821344 & 0.000250 & 0.000060 & 4.071701 \\
Health & 0.000043 & 0.000070 & 3.095017 & 0.000043 & 0.000049 & 7.842757 & 0.000043 & 0.000014 & 5.505475 \\
Within & 0.004839 & 0.007097 & 2.794212 & 0.004839 & 0.004772 & 6.685876 & 0.004839 & 0.002799 & 9.883274 \\
Between & -0.000225 & -0.000480 & 4.055908 & -0.000225 & -0.000190 & 5.777997 & -0.000225 & -0.000039 & 2.957928 \\
\hline \hline
\end{tabular}

Notes: MII is the marginal impact on inequality, $\frac{\partial I(\rho)}{\partial(.)}$; MIP, is the marginal impact on poverty, $\frac{\partial P(z ; \alpha)}{\partial(.)}$; and ELS is the elasticity of poverty with respect to inequality, $\varepsilon_{(.)}(z ; \alpha ; \rho)$. The poverty line is MK16165. 
Table A1: Elasticity of Poverty with Respect to Within- and Between-Component Inequality $(\rho=2)$ at the National Level

\begin{tabular}{lccccccccc}
\hline \hline & & \multicolumn{2}{c}{$\underline{\alpha=0}$} & & \multicolumn{3}{c}{$\underline{\alpha=1}$} & & $\underline{\alpha=2}$ \\
Source & MII & MIP & ELS & MII & MIP & ELS & MII & MIP & ELS \\
\hline Food & 0.001923 & 0.002972 & 2.698137 & 0.001923 & 0.001607 & 6.135563 & 0.001900 & 0.000417 & 4.622227 \\
Non human & 0.001830 & 0.002599 & 2.478703 & 0.001830 & 0.001299 & 5.210888 & 0.001830 & 0.000329 & 3.827413 \\
Education & 0.000104 & 0.000135 & 2.267656 & 0.000104 & 0.000062 & 4.391379 & 0.000104 & 0.000015 & 3.134318 \\
Health & 0.000043 & 0.000066 & 2.673568 & 0.000043 & 0.000036 & 6.167470 & 0.000043 & 0.000009 & 4.626291 \\
Within & 0.003900 & 0.005786 & 2.589061 & 0.003900 & 0.003004 & 5.655358 & 0.003900 & 0.001542 & 8.419012 \\
Between & -0.000446 & -0.000411 & 1.608856 & -0.000446 & -0.000122 & 2.007078 & -0.000446 & -0.000045 & 2.138807 \\
\hline \hline
\end{tabular}

Notes: MII is the marginal impact on inequality, $\frac{\partial I(\rho)}{\partial(.)}$; MIP, is the marginal impact on poverty, $\frac{\partial P(z ; \alpha)}{\partial(.)}$; and ELS is the elasticity of poverty with respect to inequality, $\varepsilon_{(.)}(z ; \alpha ; \rho)$. The poverty line is MK10029. 
Table A2: Elasticity of Poverty with Respect to Within- and Between-Component Inequality ( $\rho=2$ ) for Rural Areas

\begin{tabular}{|c|c|c|c|c|c|c|c|c|c|}
\hline \multirow[b]{2}{*}{ Source } & \multicolumn{3}{|c|}{$\underline{\alpha=0}$} & \multicolumn{3}{|c|}{$\alpha=1$} & \multicolumn{3}{|c|}{$\alpha=2$} \\
\hline & MII & MIP & ELS & MII & MIP & ELS & MII & MIP & ELS \\
\hline Food & 0.001905 & 0.002700 & 1.983597 & 0.001905 & 0.001527 & 4.701050 & 0.001905 & 0.000403 & 3.588307 \\
\hline Non human & 0.001398 & 0.001924 & 1.925166 & 0.001398 & 0.001030 & 4.320279 & 0.001398 & 0.000268 & 3.248424 \\
\hline Education & 0.000048 & 0.000064 & 1.868856 & 0.000048 & 0.000033 & 3.979568 & 0.000048 & 0.000008 & 2.943192 \\
\hline Health & 0.000041 & 0.000059 & 2.002495 & 0.000041 & 0.000034 & 4.877305 & 0.000041 & 0.000009 & 3.671611 \\
\hline Within & 0.003392 & 0.004750 & 1.959434 & 0.003392 & 0.002624 & 4.536031 & 0.003392 & 0.001377 & 6.880198 \\
\hline Between & -0.000136 & -0.000139 & 1.428844 & -0.000136 & -0.000036 & 1.555019 & -0.000136 & -0.000006 & 0.780814 \\
\hline
\end{tabular}

Notes: MII is the marginal impact on inequality, $\frac{\partial I(\rho)}{\partial(.)}$; MIP, is the marginal impact on poverty, $\frac{\partial P(z ; \alpha)}{\partial(.)}$; and ELS is the elasticity of poverty with respect to inequality, $\mathcal{E}_{(.)}(z ; \alpha ; \rho)$. The poverty line is MK10029. 
Table A3: Elasticity of Poverty with Respect to Within- and Between-Component Inequality $(\rho=2)$ for Urban Areas

\begin{tabular}{|c|c|c|c|c|c|c|c|c|c|}
\hline & & $\underline{\alpha=0}$ & & & $\underline{\alpha=1}$ & & & $\underline{\alpha=2}$ & \\
\hline Source & MII & MIP & ELS & MII & MIP & ELS & MII & MIP & ELS \\
\hline Food & 0.001694 & 0.002350 & 8.905758 & 0.001694 & 0.001065 & 8.904217 & 0.001694 & 0.000237 & 3.379656 \\
\hline Non human & 0.002852 & 0.003306 & 7.440257 & 0.002852 & 0.001352 & 4.249883 & 0.002852 & 0.000294 & 9.853879 \\
\hline Education & 0.000250 & 0.000272 & 6.973048 & 0.000250 & 0.000103 & 2.378596 & 0.000252 & 0.000022 & 8.450416 \\
\hline Health & 0.000043 & 0.000059 & 8.816493 & 0.000043 & 0.000023 & 6.296120 & 0.000043 & 0.000006 & 2.951218 \\
\hline Within & 0.004839 & 0.006394 & 8.481313 & 0.004839 & 0.002543 & 5.800556 & 0.004839 & 0.001119 & 2.086187 \\
\hline Between & -0.000225 & -0.000181 & 5.161551 & -0.000225 & 0.000039 & 5.167408 & -0.000225 & -0.000008 & 3.316314 \\
\hline
\end{tabular}

Notes: MII is the marginal impact on inequality, $\frac{\partial I(\rho)}{\partial(.)} ;$ MIP, is the marginal impact on poverty, $\frac{\partial P(z ; \alpha)}{\partial(.)}$; and ELS is the elasticity of poverty with respect to inequality, $\varepsilon_{(.)}(z ; \alpha ; \rho)$. The poverty line is MK10029. 